\title{
Modeling and Transient Simulation of Unified Power Flow Controllers (UPFC) in Power System Studies
}

\author{
B. Kawkabani, Member, IEEE, Y. Pannatier, J.-J. Simond, Member, IEEE
}

\begin{abstract}
The present paper describes the modeling of Unified Power Flow Controllers (UPFC) for studying the steady-state and transient behavior of electrical networks equipped with FACTS devices. Detailed time-domain simulations are carried out on four model power systems (single-machine system and multi-machine systems including the IEEE-14 bus test system), to illustrate the control features of these devices and their influence to increase power transfer and improve system stability. The interaction between the UPFC, the network and the machines are analyzed.
\end{abstract}

Index Terms-FACTS, UPFC, device modeling, power transmission, transient simulation.

\section{INTRODUCTION}

$\mathrm{I}_{\mathrm{n}}$ interconnected power systems, it is important to have control over power transfer. This can improve stability and allow transmission lines to be loaded closer to their thermal limits. In order to have a better use of the transmission capabilities of the transmission lines, different types of FACTS devices have been studied: static compensator (STATCOM), thyristor-controlled series compensator (TCSC), thyristor-controlled phase shifting transformer (TCPST). Among the FACTS devices, the unified power flow controller (UPFC) is a power electronics-based system considered as the most powerful, which can provide full dynamic control of the parameters of a transmission line: bus voltage, line impedance and phase angle.

The modeling of FACTS devices is an important aspect to be considered in the design. Different studies [1]-[4] investigated different control strategies as well as the steadystate operation of the FACTS devices, but the system transient behavior is not fully studied. Models used in dynamic

B. Kawkabani is with the Laboratory for Electrical Machines, Swiss Federal Institute of Technology, 1015 Lausanne, Switzerland (phone: 00 4121-693 26 80; fax: 00 4121-693 26 87; e-mail: basile.kawkabani@ epfl.ch).

Y. Pannatier, is with the Laboratory for Electrical Machines, Swiss Federal Institute of Technology, 1015 Lausanne, Switzerland (e-mail: yves.pannatier@epfl.ch).

J.-J. Simond is director of the Laboratory for Electrical Machines, Swiss Federal Institute of Technology, 1015 Lausanne, Switzerland (e-mail: jeanjacques.simond@epfl.ch). simulation programs represent generally the FACTS devices by simplified models (fundamental waves). This aspect may be restrictive for the investigation in details of the power quality and the dynamic performances of the UPFC.

In this study, in order to fulfill these requirements, the purpose of the model considered for the UPFC is to represent correctly the switching action of the semiconductors (GTO or IGCT semiconductors) in the FACTS units in the time and in three-phase. This model has been implemented in the SIMSEN software package [5]. This numerical software package, developed by the EPFL laboratory for Electrical Machines permits the simulation in transient and in steadystate conditions of electrical networks and adjustable speed drives having an arbitrary topology [6], [7]. The paper presents different simulations carried out on four model power systems (single-machine system and multi-machine systems including the IEEE-14 bus test system), and the modeling of a 2-level UPFC with its control system.

\section{BASIC TOPOLOGY OF UPFC}

The topology of a 2-level UPFC is given in Fig.1.

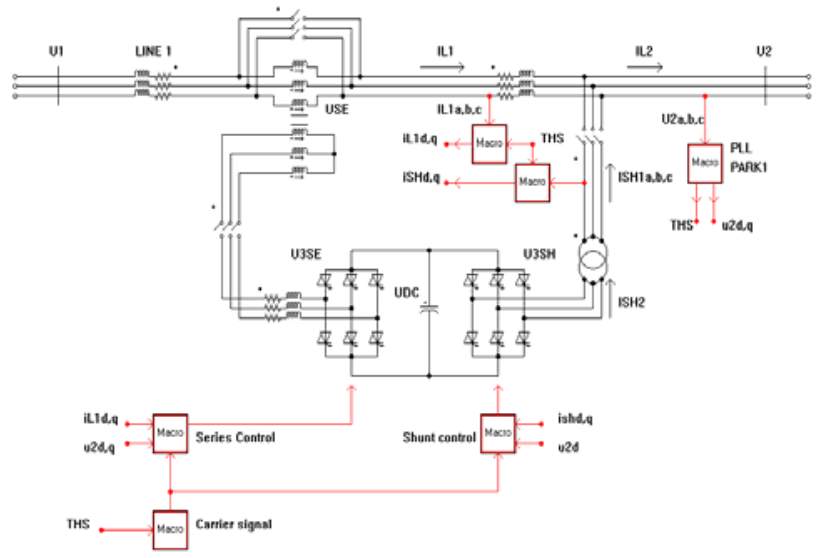

Fig.1. Topology of a 2-level UPFC

The converter on the right side is called shunt compensator and is connected to the bus 2 through the shunt transformer, whose role is to produce or consume reactive power in order to support the voltage at this bus. Another function of the shunt compensator is to control the DC voltage of the converter. The other converter, on the left side, is called series 
compensator and is connected to the transmission line through a special transformer, whose function is to insert a voltage Use in series with the transmission line in order to control the active and reactive power flows through the line.

\section{MODELING OF UPFC}

\section{A. Transfer functions of parallel and series parts}

In order to develop a control strategy, it is necessary to model UPFC with transfer functions. Fig. 2 represents the simplified electric scheme of a 2-level UPFC.

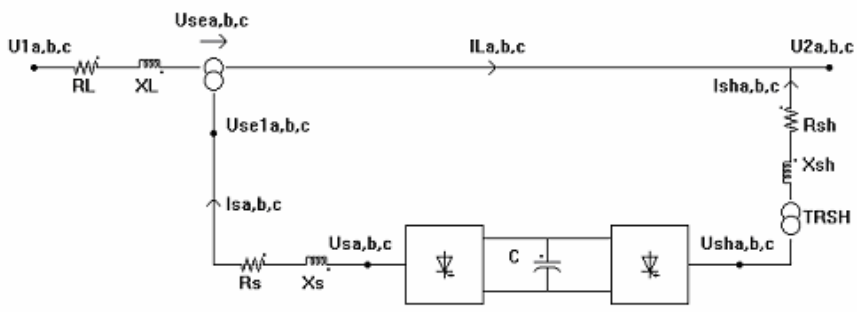

Fig. 2: Simplified electric scheme of a 2-level UPFC.

The modeling of series and parallel parts of UPFC [2], [8] can be represented respectively by the following equations expressed in a d,q rotating system, which is defined such that the $\mathrm{q}$ component of the voltage at the second bus equals to zero:

$$
\begin{aligned}
& R_{t} \underline{I}_{L}+L_{t} \frac{d}{d t} \underline{I}_{L}+j \omega L_{t} \underline{I}_{L}=\underline{U}_{1}-\ddot{u}_{s e} \cdot \underline{U}_{s}-\underline{U}_{2} \\
& R_{s h} \underline{I}_{s h}+L_{s h} \frac{d}{d t} \underline{I}_{s h}+j \omega L_{s h} \underline{I}_{s h}=\frac{1}{\ddot{u}_{s h}} \underline{U}_{s h}-\underline{U}_{2}
\end{aligned}
$$

$R_{t}=R_{L}+\ddot{u}_{s e}{ }^{2} R_{s}$

$L_{t}=L_{L}+\ddot{u}_{s e}^{2} L_{s}$

$\ddot{u}_{s e}$ and $\ddot{u}_{s h}$ represent respectively the voltage ratios of the series and parallel transformers.

The transfer functions related to these two equations expressed in per unit and represented in the Laplace domain are given in TABLE 1 .

TABLE I

\begin{tabular}{|c|c|}
\hline SERIES PART & $\frac{1}{r_{t}}$ \\
\hline$G_{s}(s)=\frac{i_{L}}{\underline{u}}=\frac{\text { SHUNT PART }}{1+(s+j \omega) T_{t}}$ & $G_{s}(s)=\frac{\frac{i_{s h}}{u}}{\underline{u}} \frac{\frac{1}{r_{s h}}}{1+(s+j \omega) T_{s h}}$ \\
with $T_{t}=\frac{l_{t}}{r_{t}}$ & with $T_{s h}=\frac{l_{s h}}{r_{s h}}$ \\
\hline
\end{tabular}

\section{B. Control system}

The next step is to develop a control strategy in the d,q rotating system for each part. The active and reactive powers can be calculated directly in the rotating system and depend on the voltage at the second bus and on the current in the transmission line.

$p=u_{2 d} i_{L d}$

$q=-u_{2 d} i_{L q}$

As the voltage at the second bus is supported by the shunt compensator, $\mathrm{p}$ and $\mathrm{q}$ can be controlled directly by acting on the components $\mathrm{d}$ and $\mathrm{q}$ of the current in the transmission line. So the control strategy of the series part can be illustrated by the standard block diagram of Fig. 3 that includes a regulator, a control element and the transfer function of the series UPFC branch.

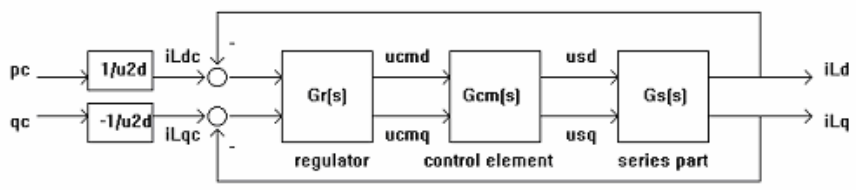

Fig. 3. Block diagram of series part control

The transfer functions of the control element and of the regulator can be determined with the "méplat" criterion [9] and are given by the following relations:

$G_{c m}(s)=\frac{\underline{u}_{s}}{\underline{u}_{c m}}=\frac{K_{c m}}{1+(s+j \omega) T_{c m}}$

$G_{r}(s)=\frac{\underline{u}_{c m}}{\underline{i}_{L c}-\underline{i}_{L}}=\frac{1+(s+j \omega) T_{n}}{s T_{i}}$

Concerning the parallel UPFC branch, its roles are to support the voltage at the second bus and to control the DC voltage of the converter. As known, the support voltage can be realized by producing or consuming reactive power at the bus. This reactive power depends on the voltage at the second bus and the q component of the current circulating in the shunt transformer and can be calculated as follows:

$q=-u_{2 d} i_{s h q}$

The same development can be done for the control of the DC voltage of the converter. Actually, it is possible to obtain a transfer function linking this voltage and the $d$ component of the current in the parallel part.

$G_{D C}(s)=\frac{U_{D C}}{i_{s h d}}=\frac{1}{s C}$

As for the series part, the control strategy of the parallel UPFC branch can be illustrated by the standard block diagram of Fig. 4.

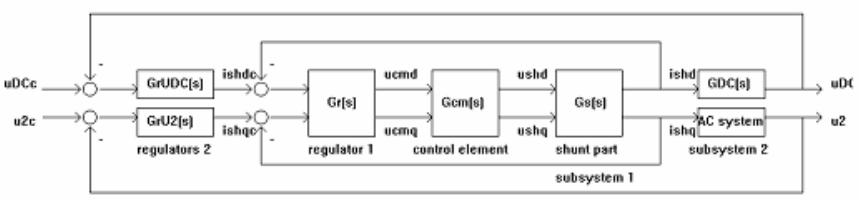

Fig.4. Block diagram of parallel part control 
The regulator in the internal control loop is determined with the "méplat" criterion. So its transfer function and the control element's one are also given by relations (7) and (8). Concerning the external control loop, the regulator is determined with the "symmetrical" criterion [9], due to the integral behavior of the system. The transfer function of this regulator is given by:

$$
G_{r U D C}(s)=\frac{1+s T_{n}}{s T_{i}}
$$

\section{STUDIED SYSTEMS}

Four model power systems have been studied in order to illustrate the control features of the UPFC.

\section{A. Change of active and reactive power set values}

To investigate the dynamic behavior of the UPFC, fast changes of the active and reactive powers (two triangular power steps of 0.2 second) are applied to the control of the system given in Fig.1. At 0.05 second, the reference set values are set to $80 \%$ active and $60 \%$ reactive powers flowing through the transmission line LINE1. At $0.3 \mathrm{sec}$, the reference set value for the active power only is set to $100 \%$. Fig. 5 shows the active and reactive powers in the transmission line 1. During all the period where power is flowing through the transmission line, one can observe the same apparent power. As the voltage is maintained by the parallel UPFC branch, this leads to the same phase currents amplitudes as shown in Fig. 6.

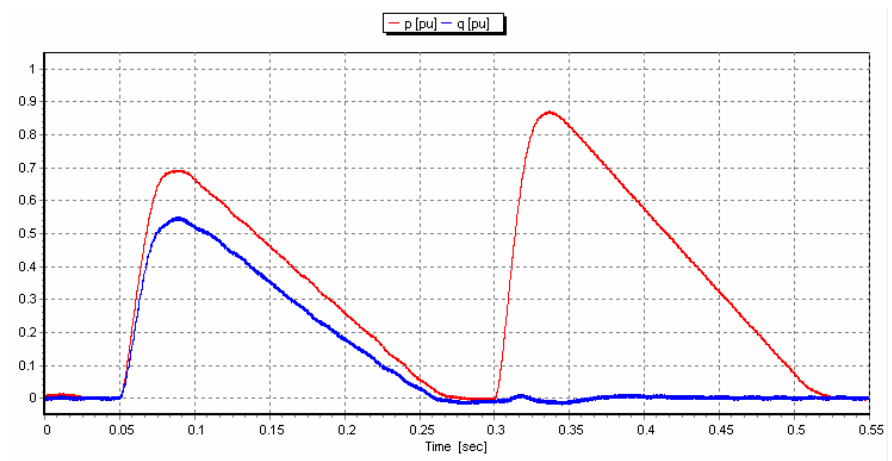

Fig.5. Active and reactive powers in the transmission line LINE1 (2-level UPFC)

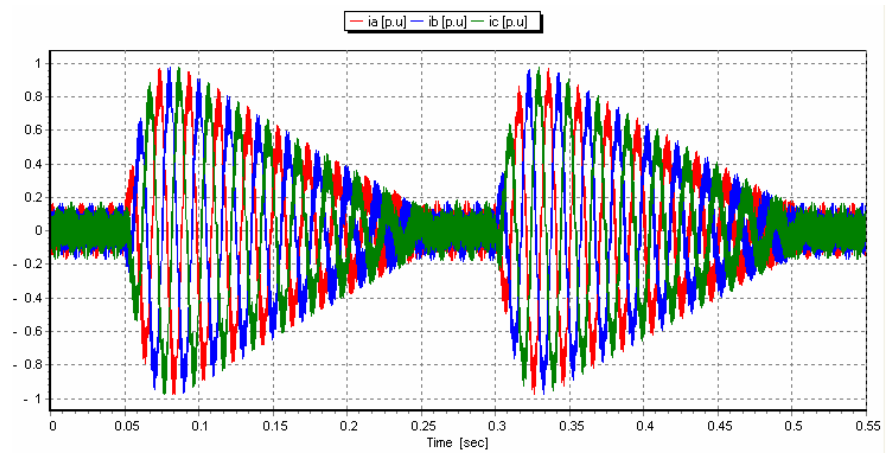

Fig.6. Currents in the transmission line LINE1 (2-level UPFC)
One can notice the high dynamic of the UPFC and that there is almost no coupling between the active and reactive powers. If one considers the currents in the transmission line between 0 and 0.05 second, the fundamental of the current is equal to 0 because the apparent power is equal to 0 during this time. A Fourier series analysis given in Fig. 7 shows high frequency harmonics $(850$ and $950 \mathrm{~Hz})$.

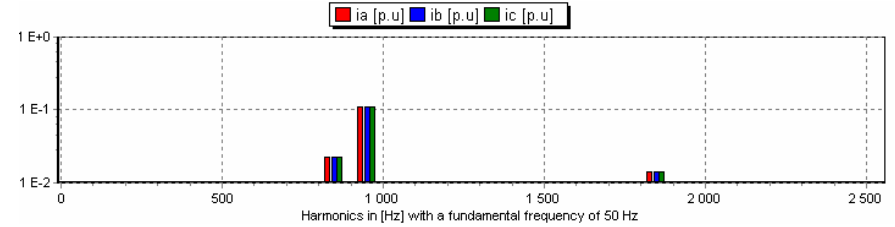

Fig.7. Fourier series analysis of the currents in the transmission line LINE1 (2-level UPFC)

Fig. 8 shows the results obtained by considering the transmission line LINE1 with a 3-level UPFC. One can notice that the harmonics amplitudes decrease significantly.

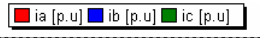

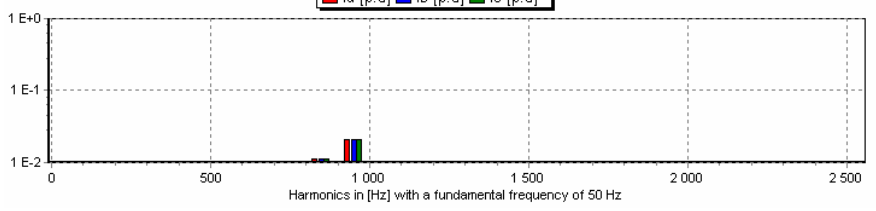

Fig.8. Fourier series analysis of the currents in the transmission line LINE1 (3-level UPFC)

\section{B. Bus support voltage}

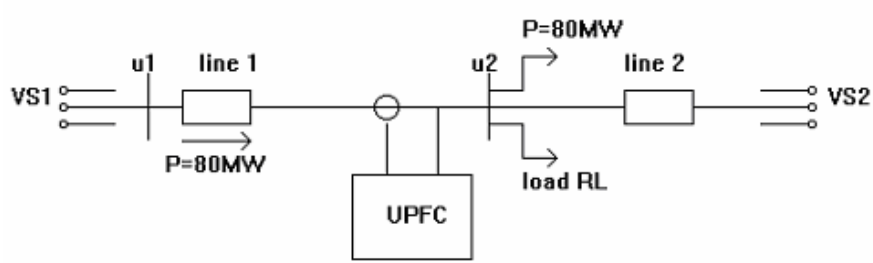

Fig.9. Model power system with a 2-level UPFC

The system studied in this case is represented in Fig. 9. It consists on two ideal voltage supply $(400 \mathrm{kV})$ and two lines, one of them equipped with a 2-level UPFC. A constant load with an active power of $80 \mathrm{MW}$ is connected to the bus 2 . The power flows in the line 1 are fixed to $80 \mathrm{MW}$ and $0 \mathrm{MVAr}$ by the series part of the UPFC. After 0.02 second, a passive RL load (5 MW, $75 \mathrm{MVAr}$ ) is also connected to the bus 2. As the power flows in the line 1 are fixed, this additional power has to be produced by the VS2 voltage supply. Fig. 10 shows the behavior of the voltage at the bus 2 without and with the support voltage due to the parallel UPFC branch.

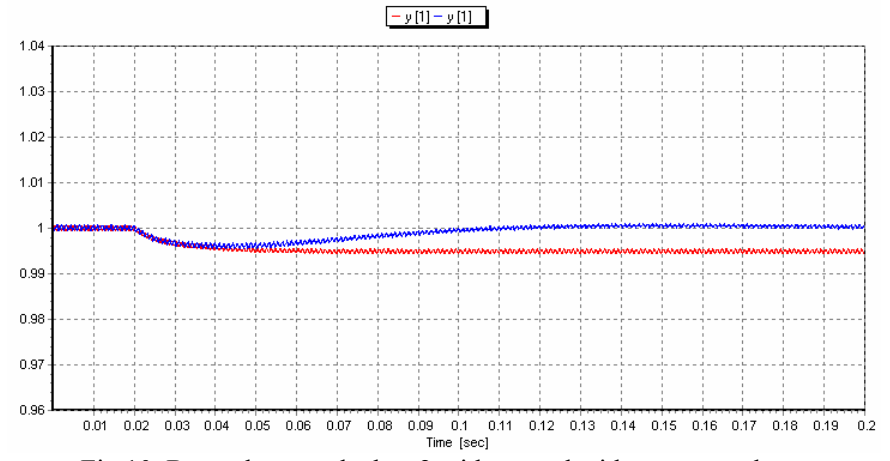

Fig.10. Bus voltage at the bus 2 without and with support voltage 
Fig. 11 and 12 represent the reactive power in the shunt transformer, respectively in the line 2 . One can notice that when the voltage at the second bus decreases, the shunt transformer is producing reactive power to compensate the reactive power flow through the line 2 in order to support the voltage at the second bus.

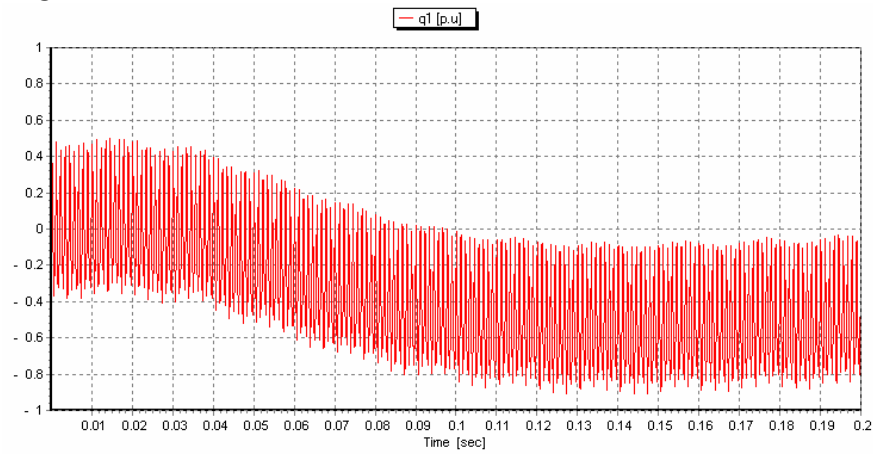

Fig.11. Reactive power in the shunt transformer.

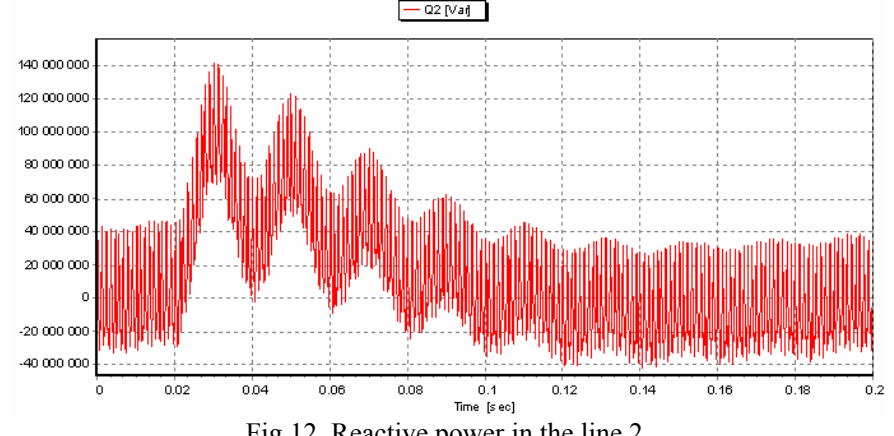

Fig.12. Reactive power in the line 2.

Fig. 13 represents the active and reactive power flows in the line 1. These are fixed by the series part of the UPFC. The active power flows in the constant load and the active and reactive powers in the passive RL load are represented in Fig. 14.

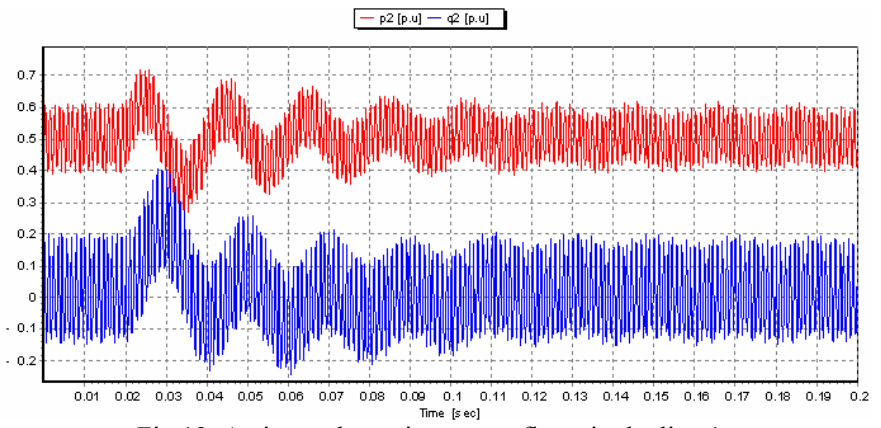

Fig.13. Active and reactive power flows in the line 1.

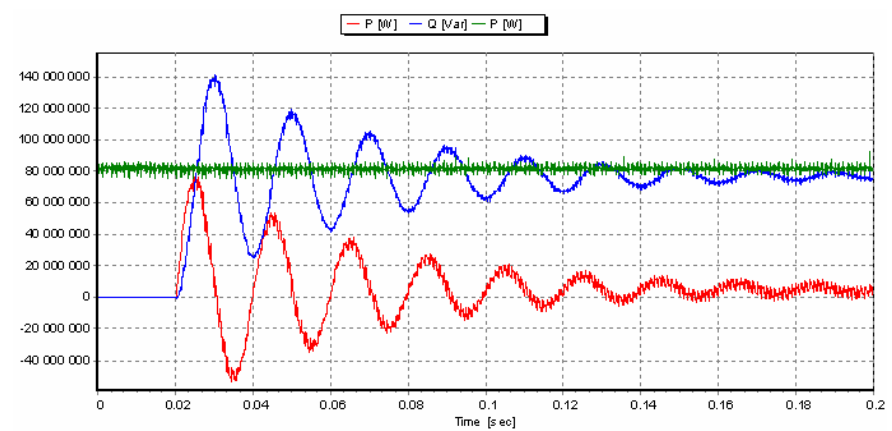

Fig.14. Active power in the constant load and power flows in the RL load.

\section{Power flows control in transmission lines}

Fig. 15 shows a 190 MVA synchronous machine connected to an AC grid through a transformer and two lines in parallel. Only the line 1 is equipped with a 2-level UPFC. The capacity of the line $1 \mathrm{~B}(80 \mathrm{MW})$ is lower than the one of the line 1 (160 MW).

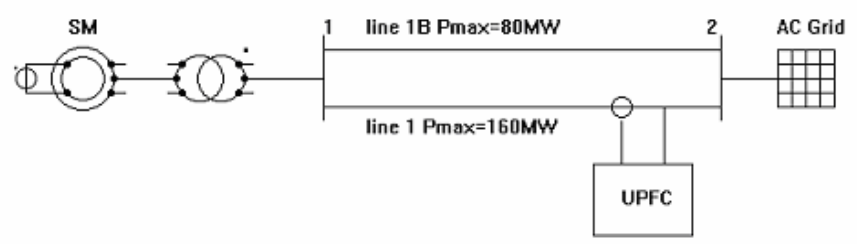

Fig.15. Model power system with a single-machine and two parallel lines

Two cases are considered. In the first case, the 2-level UPFC is out of service. The synchronous machine produces $75 \mathrm{MW}$ which is delivered to the $\mathrm{AC}$ grid through the line 1 $(25 \mathrm{MW})$ and line $1 \mathrm{~B}(50 \mathrm{MW})$. No line is overloaded. At 100 ms due to a demand of the AC network, the production at bus 1 is increased to $140 \mathrm{MW}$. The maximum capacity of the line $1 \mathrm{~B}$ is reached after $3 \mathrm{sec}$ as shown in Fig. 16.

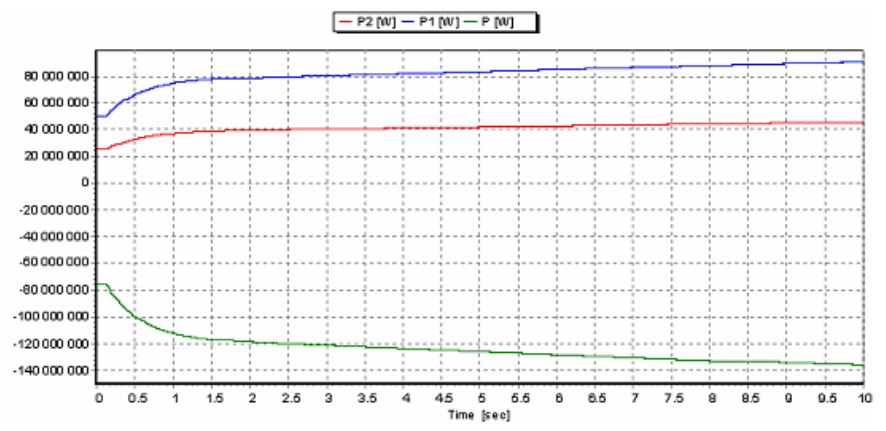

Fig.16. Active and reactive powers in the lines 1 and $1 \mathrm{~B}$, and active power delivered by the synchronous machine, without UPFC.

Fig. 17 shows the power flows in the lines 1 and $1 \mathrm{~B}$ when the UPFC is operating. The power flowing in the line 1 is set by the UPFC to $50 \mathrm{MW}$. At $100 \mathrm{~ms}$, the production at bus 1 increases. When the maximum capacity of line $1 \mathrm{~B}$ is reached, the reference power of line 1 is adapted in order to prevent the overload of the line 1B.

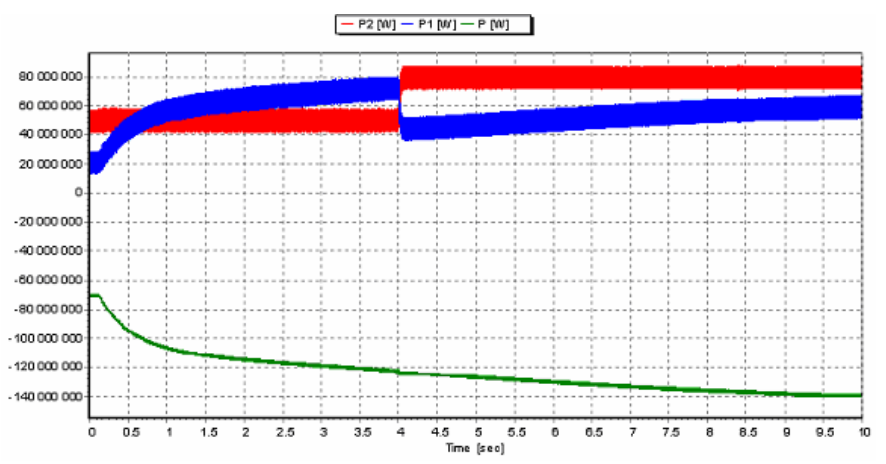

Fig.17. Active and reactive powers in the lines 1 and $1 \mathrm{~B}$, and active power delivered by the synchronous machine, with UPFC. 


\section{Standard IEEE-14 bus test system}

Fig. 18 shows the standard IEEE-14 bus test system used in this case to study the behavior of multiple UPFC installed in a network with weak voltage profile [4]. The implementation of this test system in SIMSEN has been realized for purpose comparisons, even if the last case simulated representing an increase of $400 \%$ of the load is not so realistic. In the system, there are 20 branches, 2 synchronous generators, 3 synchronous compensators. The HV lines (1-2 to 4-5) have been considered with their three phase PI model transmission line. Fig. 19 represents the implementation in SIMSEN of the area related to the busses N9 to N14. The total number of modules for this power system is equal to 282 . The parameters of the lines and the machines rated values are given in Tables II and III in Appendix.

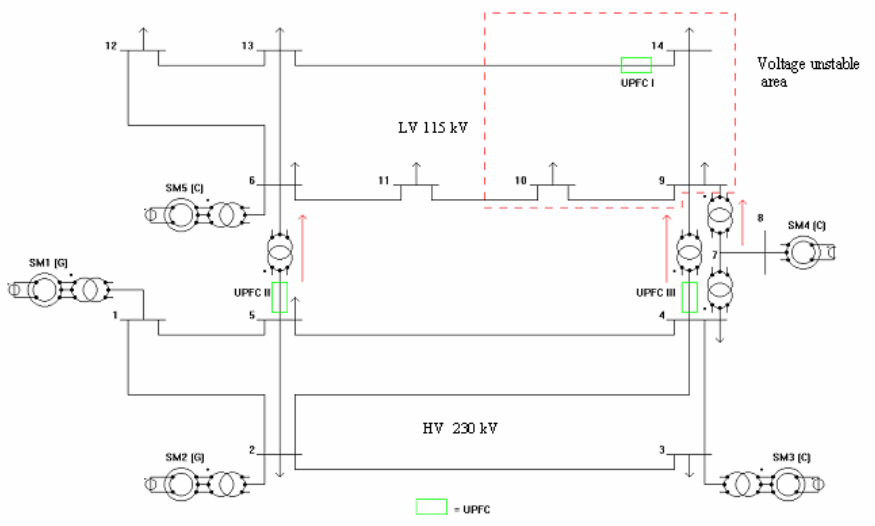

Fig.18. Single line diagram of the IEEE-14 bus test system.

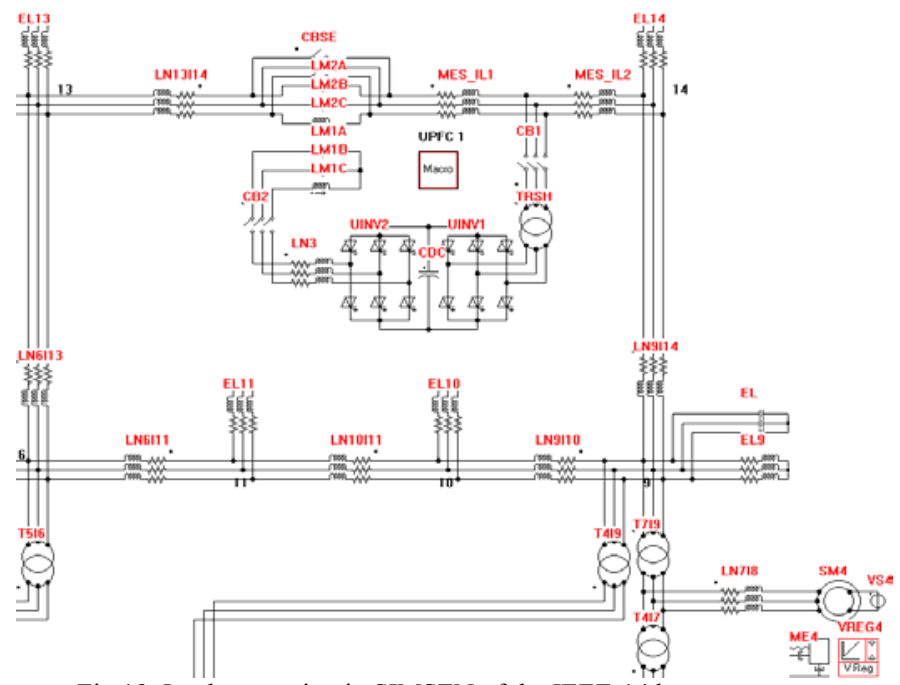

Fig.19. Implementation in SIMSEN of the IEEE-14 bus test system.

The load of the network is increased by $400 \%$ of the initial load by steps of $100 \%$. It is assumed that, when the load is increased, the transmission lines remain operating below their thermal limits and the two synchronous generators are increasing the production in order to satisfy the increase of load [4]. Fig. 20 represents the voltages profiles under load conditions without UPFC. It can be noticed that there is an unstable voltage area constituted by the busses N9, N10, N14.

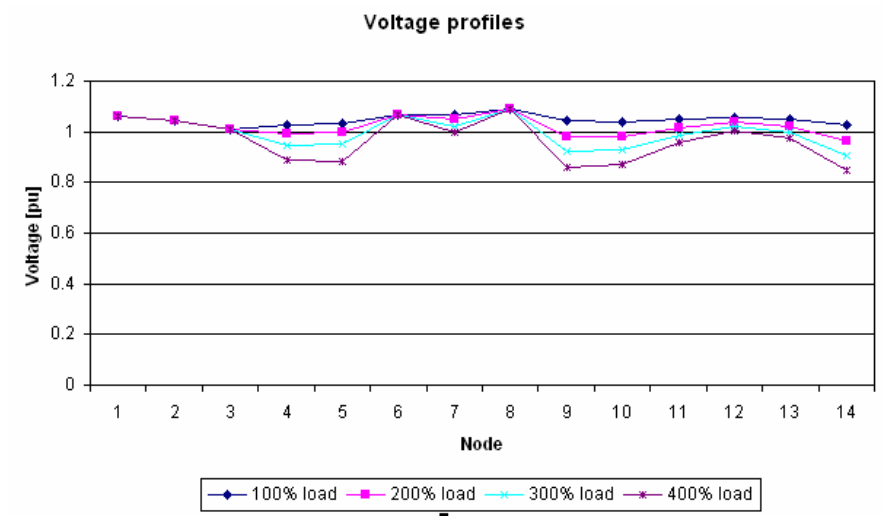

Fig.20. Voltage profiles under different loading conditions without UPFC.

By installing 3 UPFC in the lines $\mathrm{N}_{5}-\mathrm{N}_{6}, \mathrm{~N}_{4}-\mathrm{N}_{9}, \mathrm{~N}_{13}-\mathrm{N}_{14}$ as shown in Fig. 18, the three UPFC support the voltages at the busses $\mathrm{N}_{4}, \mathrm{~N}_{5}, \mathrm{~N}_{14}$ and the two UPFC installed in the line $\mathrm{N}_{5^{-}}$ $\mathrm{N}_{6}$ and in the line $\mathrm{N}_{4}-\mathrm{N}_{9}$ control the active power flow. Fig. 21 shows the voltage profiles under $100 \%$ load, $400 \%$ load without and with UPFC.

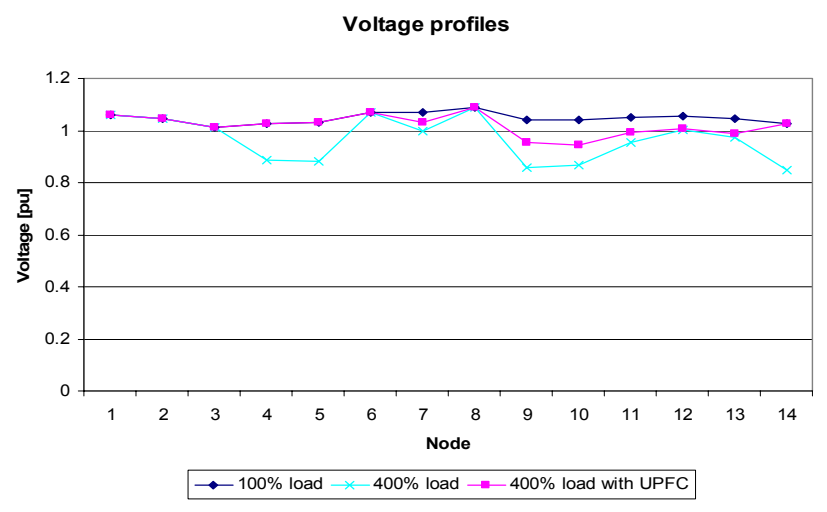

Fig.21. Voltage profiles with 3 UPFC installed in the network.

Results obtained by this study are in good agreement with those published in [4]. One can notice that the voltage profiles of a network with an unstable voltage area can be improved noticeably by the use of multiple UPFC adequately located in the network. Furthermore, one may analyze precisely all the quantities (voltages, currents, active and reactive powers, aso) related to any element of this test system.

\section{CONCLUSION}

The present paper deals with the study of steady-state and transient behavior of electrical networks equipped with UPFC devices. The modeling of a 2-level UPFC and its control system is presented. Comparing to simplified models, the model considered for the UPFC represents correctly the behavior of the semiconductors (GTO or IGCT), thus simulation results are close to the real behavior of such devices. This precise model permits also to investigate the power quality and the dynamic performances of the UPFC. The interaction between the UPFC, the network and the machines are analyzed and carried out on four model power systems. The application related to the IEEE 14-bus test system has been implemented successfully in SIMSEN. Simulation results could only be compared with 
published results obtained with simplified models [4]. Nevertheless, this comparison can be considered as a qualitative test. Further investigations of the performances and interactions between PSS and several FACTS controllers in the IEEE 14bus test system have to be done.

\section{APPENDIX}

TABLE II

LINE PARAMETERS OF THE IEEE-14 BUS SYSTEM

\begin{tabular}{|c|c|c|c|c|}
\hline Line & $\begin{array}{c}\text { Voltage } \\
\text { reference }\end{array}$ & R [pu] & X [pu] & B [pu] \\
\hline $1-2$ & HV & 0.01938 & 0.05917 & 0.0528 \\
\hline $1-5$ & HV & 0.05403 & 0.22304 & 0.0492 \\
\hline $2-3$ & HV & 0.04699 & 0.19797 & 0.0438 \\
\hline $2-4$ & HV & 0.05811 & 0.17632 & 0.0374 \\
\hline $2-5$ & HV & 0.05695 & 0.17388 & 0.034 \\
\hline $3-4$ & HV & 0.06701 & 0.17103 & 0.0346 \\
\hline $4-5$ & HV & 0.01335 & 0.04211 & 0.0128 \\
\hline $4-7$ & HV & 0 & 0.20912 & 0 \\
\hline $4-9$ & HV & 0 & 0.55618 & 0 \\
\hline $5-6$ & HV & 0 & 0.25202 & 0 \\
\hline $6-11$ & LV & 0.09498 & 0.1989 & 0 \\
\hline $6-12$ & LV & 0.12291 & 0.25581 & 0 \\
\hline $6-13$ & LV & 0.06615 & 0.13027 & 0 \\
\hline $7-8$ & TV & 0 & 0.17615 & 0 \\
\hline $7-9$ & LV & 0 & 0.11001 & 0 \\
\hline $9-10$ & LV & 0.03181 & 0.0845 & 0 \\
\hline $9-14$ & LV & 0.12711 & 0.27038 & 0 \\
\hline $10-11$ & LV & 0.08205 & 0.19207 & 0 \\
\hline $12-13$ & LV & 0.22092 & 0.19988 & 0 \\
\hline $13-14$ & LV & 0.17093 & 0.34802 & 0 \\
\hline
\end{tabular}

TABLE III

MACHINES VALUES OF THE IEEE-14 BUS SYSTEM

\begin{tabular}{|c|c|c|c|c|}
\hline Machine & Type & $\begin{array}{c}\text { Voltage } \\
{[\mathrm{kV}]}\end{array}$ & $\begin{array}{c}\text { Rated } \\
\text { power } \\
{[\mathrm{MVA}]}\end{array}$ & $\mathrm{P}[\mathrm{MW}]$ \\
\hline SM1 & $\mathrm{G}$ & 15 & 615 & 232.4 \\
\hline SM2 & $\mathrm{G}$ & 13.8 & 60 & 40 \\
\hline SM3 & $\mathrm{C}$ & 13.8 & 60 & 0 \\
\hline SM4 & $\mathrm{C}$ & 13.8 & 25 & 0 \\
\hline SM5 & $\mathrm{C}$ & 13.8 & 25 & 0 \\
\hline
\end{tabular}

\section{REFERENCES}

[1] J.-C Passelergue, N. Hadjsaïd, Y. Bésanger, R. Feuillet, "On using Facts and power system stabilizers to damp low frequency oscillations," EPE'97, $7^{\text {th }}$ European Conference on Power Electronics and Applications, Trondheim, Norway, September 1997.

[2] I. Papic, P. Zunko, D. Povh, M.Weinhold, "Basic control of Unified Power Flow Controller," IEEE Transactions on Power Systems, Vol.12, No.4, November 1997, pp. 1734-1739.

[3] D. Povh, "Application of FACTS to systems," EPSOM'98, International Conference on Electrical Power Systems Operation and Management, Vol 1, Zurich, Switzerland, September 1998.

[4] S. Dupuis, M. Crappe, J. Trécat, K.L. Lo, T.T. Ma, K. Karoui, "Study of the optimal location and control of UPFCs in a standard power system by simulation with Eurostag," EPE'99, $8^{\text {th }}$ European Conference on Power Electronics and Applications, Lausanne, Switzerland, September 1999.

[5] http://simsen.epfl.ch
[6] J.-J. Simond, A. Sapin, B. Kawkabani, D. Schafer, M. Tu Xuan, B. Willy, "Optimized design of variable speed drives based on numerical simulation," EPE'97, $7^{\text {th }}$ European Conference on Power Electronics and Applications, Trondheim, Norway, September 1997.

[7] A. Sapin, J.-J. Simond, Ph. Allenbach, B, "Investigation of the 3-Level Unified Power Flow Controller (UPFC)," EPE 2001, $9^{\text {th }}$ European Conference on Power Electronics and Applications, Graz, Austria, August 2001.

[8] H. Bühler, "Réglage de systèmes d'électronique de puissance," Vol. 3 : Réseaux électriques, PPUR, Lausanne, 1999.

[9] H. Bühler, "Réglage de systèmes d'électronique de puissance," Vol. 1 : Théorie, PPUR, Lausanne, 1997. 